\title{
Effects of Chemical Post-treatments on Structural and Physicochemical Properties of Silk Fibroin Films Obtained From Silk Fibrous Waste
}

\section{OPEN ACCESS}

Edited by:

Antonella Motta,

University of Trento, Italy

Reviewed by:

PaYaM ZarrinTaj,

Oklahoma State University,

United States

Simone Silva,

University of Minho, Portugal

${ }^{*}$ Correspondence:

Adriana Restrepo-Osorio

adriana.restrepo@upb.edu.co

Specialty section:

This article was submitted to Biomaterials,

a section of the journal Frontiers in Bioengineering and

Biotechnology

Received: 01 January 2020 Accepted: 03 November 2020 Published: 02 December 2020

Citation:

Puerta $M$, Peresin MS and Restrepo-Osorio A (2020) Effects of Chemical Post-treatments on Structural and Physicochemical

Properties of Silk Fibroin Films

Obtained From Silk Fibrous Waste.

Front. Bioeng. Biotechnol. 8:523949.

doi: 10.3389/fbioe.2020.523949

\begin{abstract}
Melissa Puerta ${ }^{1}$, Maria S. Peresin ${ }^{2}$ and Adriana Restrepo-Osorio ${ }^{1,3 *}$
${ }^{1}$ Grupo de Investigación Sobre Nuevos Materiales, Universidad Pontificia Bolivariana, Medellín, Colombia, ${ }^{2}$ Forest Products Development Center, School of Forestry and Wildlife Sciences, Auburn University, Auburn, AL, United States, ${ }^{3}$ Facultad de Ingeniería Textil, Escuela de Ingenierías, Universidad Pontificia Bolivariana, Medellín, Colombia
\end{abstract}

Silk fibroin (SF) is a protein polymer claimed to have outstanding potential for medical applications. However, because of the manufacturing process, materials from regenerated SF exhibit a higher percentage of amorphous structures. The amorphous structures cause the material to be water soluble and can significantly limit its applications in wet biological environments. In order to increase the amount of crystalline structures and decrease the water solubility of SF materials, post-treatment with alcohols is usually employed. SF can be obtained from silk fibrous wastes (SFW), usually discarded in silk textile processes. This represents an opportunity to produce materials with high added value from low-cost natural sources. In this study, SF was obtained from SFW, and films were made thereof followed by a post-treatment by immersion or in a saturated atmosphere of methanol $(\mathrm{MeOH})$ or ethanol $(\mathrm{EtOH})$, using different exposure times. The resulting films were analyzed according to crystallinity, the percentage of crystalline and amorphous structures, and thermal stability. Also, water absorption and weight loss in aqueous media were determined. The results showed a significant increase in crystalline structures in all treated samples, varying according to the type and time of exposure to post-treatment conducted. The highest increase was shown in the case of the post-treatment by immersion in $\mathrm{MeOH}$ for $1 \mathrm{~h}$, with a $23 \%$ increase over the untreated sample. This increase in crystallinity was reflected in an increase in the degradation temperature and a degradation rate of $5.3 \%$ on day 7 . The possibility of tuning the degree of crystallinity, as well as thermal stability and aqueous integrity of thin films of SFW, can be applied to adjust these materials to the requirements of specific biomedical applications.

Keywords: silk fibroin, silk fibrous waste, alcohol post-treatment, secondary structure, water stability

\section{INTRODUCTION}

Silk fibroin (SF) is a protein that can be extracted from the silk produced by the Bombyx mori silkworms. In recent years, SF has been studied for medical applications such as cutaneous wound healing (Bhardwaj et al., 2015; Panico et al., 2018), bone tissue regeneration (Ko et al., 2016), and vascular implants (Bonani et al., 2011; Wu et al., 2018), among others. This has been made possible 
thanks to its biocompatibility (Adali and Uncu, 2016), biodegradability, adequate mechanical performance (Fukayama et al., 2015), ability to promote cell growth and interaction (Unger et al., 2004), and its hemocompatibility and cytocompatibility (Fukayama et al., 2015; Adali and Uncu, 2016). SF is usually extracted from cocoons of high-quality silkworms (Rockwood et al., 2011; Tao et al., 2012; Huang et al., 2017) but there are other sources such as silk fibrous wastes (SFW). In Colombia, this waste is widely available as raw material and is provided by a few small-scale sericulture production units. Many of these production units are interested in finding alternative uses to increase the value of this waste stream. Such is the case of the Corporation for the Development of Sericulture of Cauca (CORSEDA), which produces about 20 tons/year of cocoons. It is estimated that the amount of fibrous by-products of silk can reach up to $30 \%$ by weight of the cocoons produced, in which SF is the predominant protein (Babu, 2013; Jaramillo-Quiceno and Restrepo-Osorio, 2019). The development of new value-added products from waste streams, such as the manufacture of materials from SF for medical applications, may represent an alternative solution for increasing the sustainability of the sericulture chain.

On the other hand, one of the most relevant factors for materials used for biomedical purposes is their controlled biodegradability, as this defines the possible functions and durability according to the specific application of a biomaterial (Kim et al., 2012). Due to processing methods, materials manufactured from regenerated SF may have a higher percentage of amorphous structures including random coil, $\alpha$ helix, side chains, turns, and bends. These structures are less orderly and have weak bonds, making the material water soluble and giving the SF reduced mechanical properties (Kim et al., 2012; Babu, 2013). Therefore, post-treatments are required to enrich and control the quantity of crystalline structures of the SF, known as $\beta$ sheets and $\beta$-turns, which allows for tuning of properties including thermal stability and integrity in aqueous media. Some SF post-treatments include vapor or immersion of solvents such as EtOH and $\mathrm{MeOH}$, separated or mixed, to modify its crystalline structure and decrease its water solubility (Jeong et al., 2006; Zhang et al., 2009; Kim et al., 2012; Terada et al., 2016).

There are few reports of SFW as raw materials for biomaterials fabrication. Also, no further literature reports the post-treatment methods presented here, immersion and atmospheric saturation with ethanol $(\mathrm{EtOH})$ and methanol $(\mathrm{MeOH})$ as solvents, and their comparative effect on SF properties. In this work, we investigate the effect of post-treatment of SFW using $\mathrm{EtOH}$ and $\mathrm{MeOH}$. The followed methodology was immersion and exposure of SFW to atmosphere saturated in EtOH and $\mathrm{MeOH}$ for $15 \mathrm{~min}$ and $1 \mathrm{~h}$, independently for each treatment. Morphological, thermal, and chemical properties of the materials, in addition to crystallinity, were investigated by X-ray diffraction (XRD), Fourier transform infrared spectroscopy with attenuated total reflectance (FTIR-ATR), scanning electron microscopy (SEM), differential scanning calorimetry (DSC), weight loss, and water absorption.

\section{MATERIALS AND METHODS}

\section{Silk Fibroin Extraction}

Silk fibroin was extracted from fibrous wastes, provided by CORSEDA, following previously published procedures (Rockwood et al., 2011; Jaramillo-Quiceno et al., 2017; JaramilloQuiceno and Restrepo-Osorio, 2019). Briefly, the fibrous waste was degummed twice in a $0.5 \% \mathrm{w} / \mathrm{w}$ aqueous solution of $\mathrm{Na}_{2} \mathrm{CO}_{3}$ (MERK, Germany) at boiling point for $30 \mathrm{~min}$. The obtained SFW was dried at $60^{\circ} \mathrm{C}$ for $24 \mathrm{~h}$ and subsequently dissolved using LiBr (Sigma-Aldrich, St. Louis, MO, United States, > 99\% purity), $9.3 \mathrm{M}$ at $60^{\circ} \mathrm{C}$. The solution was dialyzed and finally microfiltered obtained an SFW aqueous solution at 5.6\% w/w. Subsequently, films were prepared by solvent casting and dried at $35^{\circ} \mathrm{C}$ until constant weight was reached. The obtained films had thicknesses $115 \pm 2 \mu \mathrm{m}$, determined with a micrometer device. The isolation process is illustrated in Figure 1.

\section{Post-treatments of Silk Fibroin Films}

Post-treatment of the SFW films was performed using EtOH (SIGMA ALDRICH > 99.8\% purity) and $\mathrm{MeOH}$ (EMSURE > 99.9\% purity), by (i) immersing the films in or (ii) exposing them to a saturated atmosphere with vapors of each of the solvents. The samples will be referred to as the following: films immersed in $\mathrm{MeOH}$ (IMeOH), exposed to $\mathrm{MeOH}$ vapor $(\mathrm{VMeOH})$, immersed in $\mathrm{EtOH}(\mathrm{IEtOH})$ and exposed to $\mathrm{EtOH}$ vapor (VEtOH). To determine the effect of post-treatment time, the properties were evaluated after $15 \mathrm{~min}$ and $1 \mathrm{~h}$ of immersion/vapor exposure. These times were chosen according to previous reports (Mandal et al., 2009; Bie et al., 2015; Srivastava et al., 2015; Zhou et al., 2016; Bagrov et al., 2017).

\section{Crystallinity}

To determine the crystallinity of the samples with and without post-treatments, an XPert PANalytical Empyrean Series II diffractometer was used with a $\mathrm{Cu}$ source. XRD patterns were obtained in a range $(2 \theta)$ between 5 and $50^{\circ}$, with a step of $0.026^{\circ}$ and time per step of $50 \mathrm{~s}$.

\section{Chemical Structure}

The effect of post-treatments on the chemical structure of SFW films with and without post-treatments was evaluated by means of the FTIR technique (Nicolet 6700 Series). 64 scans and a resolution of $4 \mathrm{~cm}^{-1}$ were recorded in a range of the absorption spectrum between 4,000 and $400 \mathrm{~cm}^{-1}$. OMNIC software was used to deconvolute the spectra in the region of amide I $(1,700-$ $1,600 \mathrm{~cm}^{-1}$ ) as detailed in previous work (Jaramillo-Quiceno and Restrepo-Osorio, 2019). This spectral region was selected as it is the most sensitive to changes in the secondary structures of the protein which originate from the $\mathrm{C}=\mathrm{O}$ stretch vibration of the amide groups together with the phase flexion of the $\mathrm{N}-\mathrm{H}$ bond and C-N bond stretch (Yang et al., 2015).

\section{Thermal Behavior}

To measure the thermal behavior of the films with and without post-treatments, DSC technique was used in a Q2000 TA 
Instruments unit. The samples were subjected to a temperature scan from 30 to $320^{\circ} \mathrm{C}$ and a heating rate of $10^{\circ} \mathrm{C} / \mathrm{min}$. In order to remove the water content in the samples and improve the baseline of thermogram, an isotherm at $120^{\circ} \mathrm{C}$ was performed prior to measurement in all cases.

\section{Absorption Water and Weight Loss in Aqueous Medium}

The integrity of films in an aqueous medium was determined by absorption water and weight loss of the SF films with and without post-treatments. The assay was carried out through deposition of dry pieces, with a known weight and with an area approximately $1 \mathrm{~cm}^{2}$, in distilled water at $37^{\circ} \mathrm{C}$. After 1 and 7 days, the samples were removed from the water, cleared of excess water, and weighed. The weight loss was determined by percentage of solubilized mass, according to Eq. 1 .

$$
\% \mathrm{WL}=\left(\mathrm{W}_{0}-\mathrm{W}_{f}\right) / \mathrm{W}_{0}
$$

where, $\mathrm{W}_{0}$ : initial weight, $\mathrm{W}_{f}$ : final weight after water medium exposure of dried samples.

\section{Morphology}

The effect of post-treatments and exposure to aqueous medium on morphology of the surface, and the cross-section of the films was observed with an SEM, JEOL JSM-6490 LV. Samples were cryofractured and sputtered with gold prior to the imaging. The acceleration voltage was $15 \mathrm{kV}$ and approaches were made to $\times 2,000, \times 5,000$ for surface, and $\times 1,500$ for cross-section images.
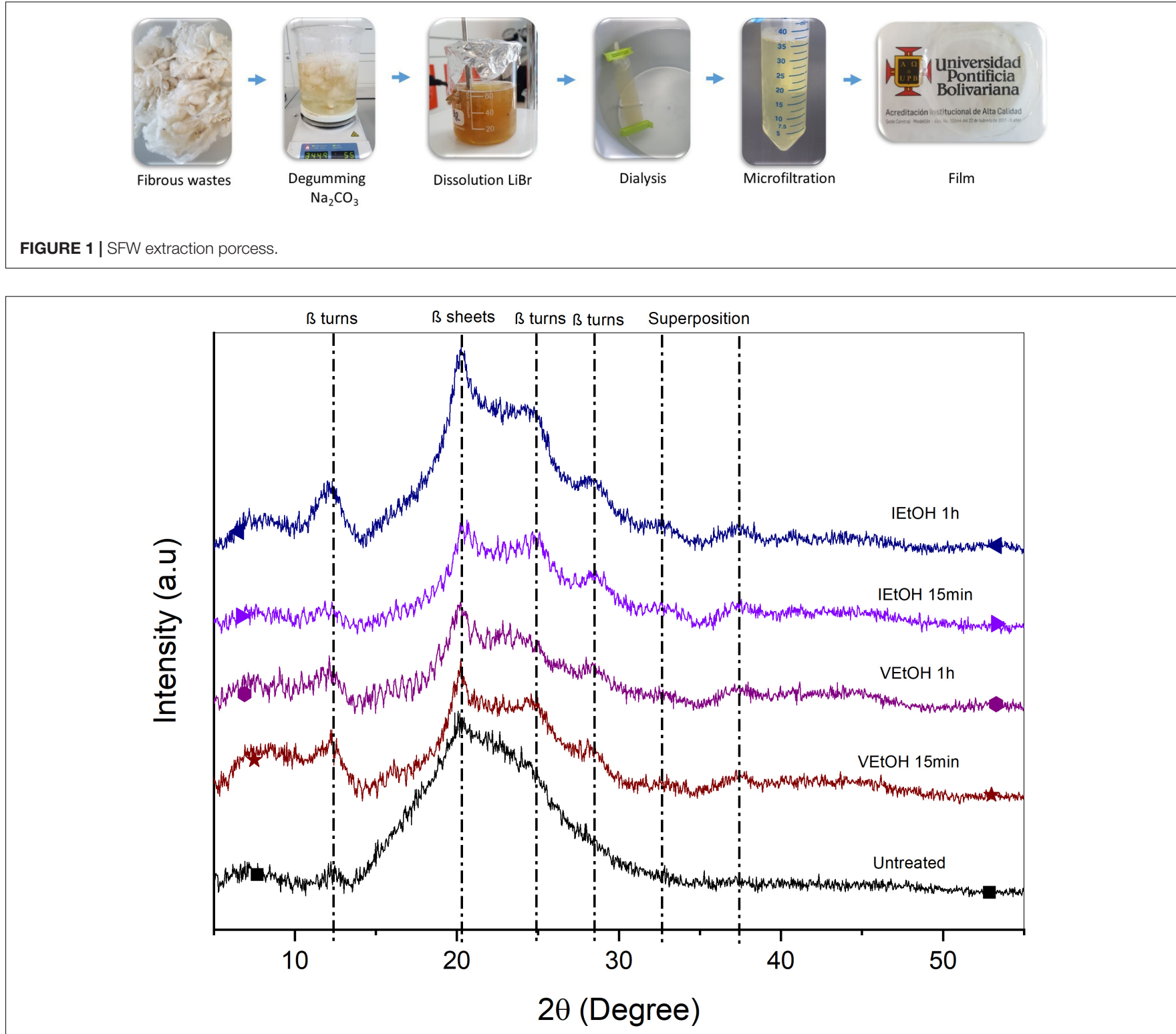

FIGURE 2 |XRD untreated and treated films with $\mathrm{EtOH}$. 


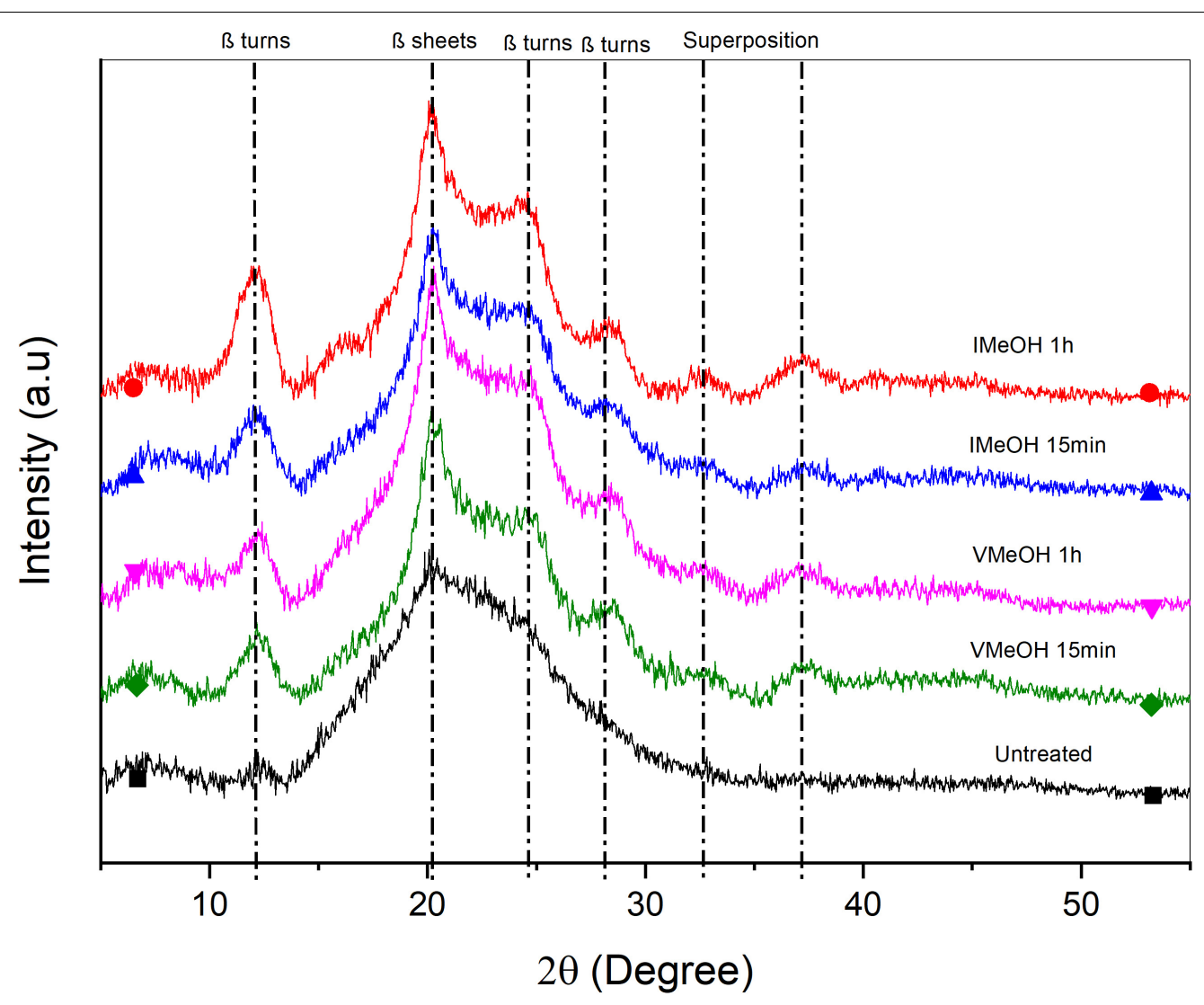

FIGURE 3 |XRD untreated and treated films with $\mathrm{MeOH}$.

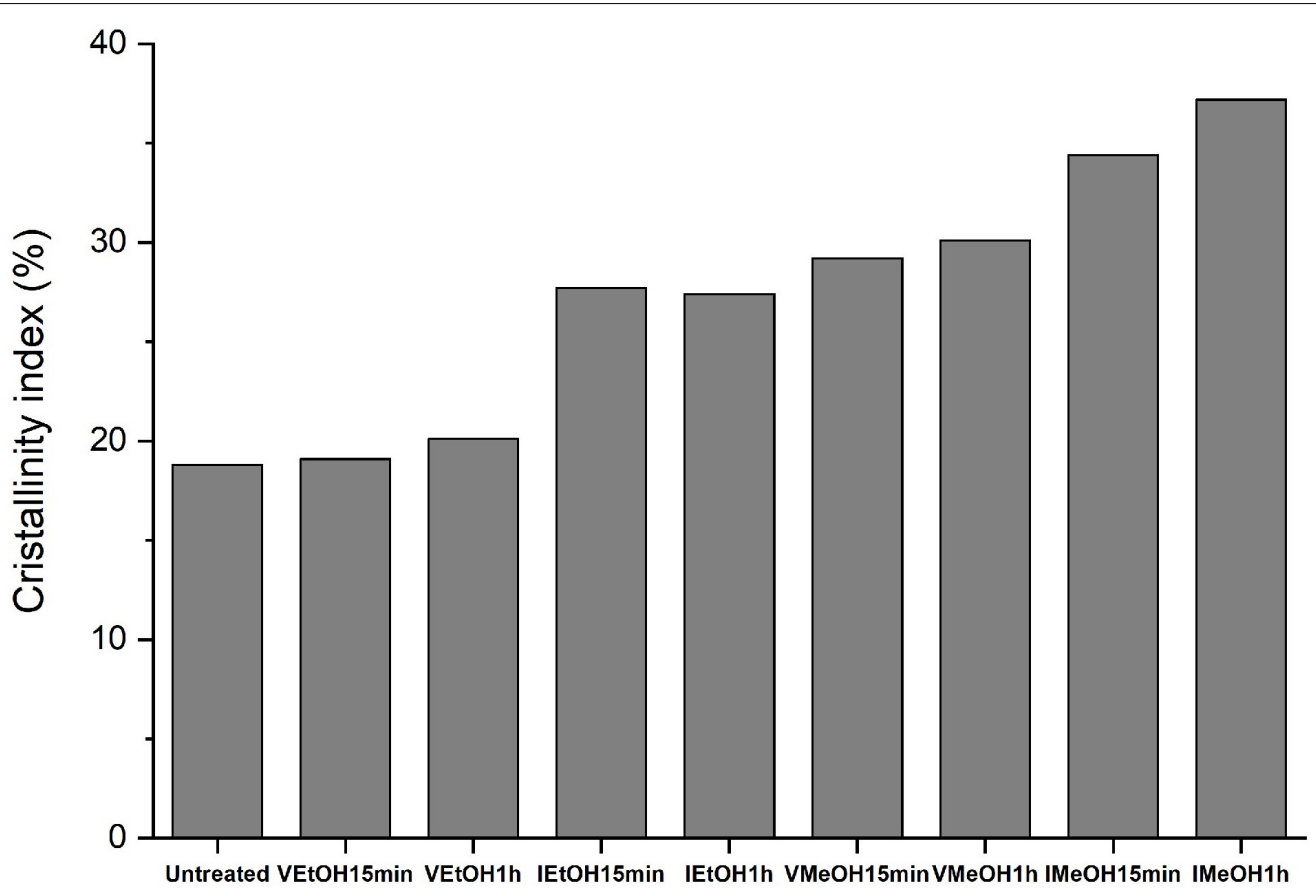

FIGURE 4 | XRD crystallinity index of untreated and treated films. 


\section{Statistical Analysis}

The effect of post-treatments on films crystallinity (FTIRATR), absorbed water and weight loss in water media test was assessed by applying ANOVA one way, with $n=3$ for each assessed condition.

\section{RESULTS AND DISCUSSION}

\section{Crystallinity}

$\mathrm{X}$-ray diffraction was utilized to determine changes in crystallinity ratio attributed to post-treatment. Figures 2, 3 show the diffractograms of the films treated with EtOH and $\mathrm{MeOH}$, respectively. Untreated films present a broad peak and low intensity at $2 \theta=19.9^{\circ}$ representative of random coil structures consistent with that reported in the literature (Nogueira et al., 2010). On the other hand, samples treated with $\mathrm{MeOH}$ and $\mathrm{EtOH}$ exhibit a defined peak at $2 \theta=20.1^{\circ}$ associated with $\beta$ sheets (silk II) (Yan et al., 2012) and attenuated peaks at $2 \theta=12.2^{\circ}, 24.7^{\circ}$, and $28.6^{\circ}$ corresponding to $\beta$ turns (silk I) (Ha et al., 2005; Wongpanit et al., 2007; Yan et al., 2012; Zhou et al., 2016). In addition, there are two other peaks at $2 \theta=32^{\circ}$ and $37^{\circ}$, which can be attributed to the superposition of other specific peaks of the SF around $2 \theta=24.71^{\circ}$ (silk I), $18.40^{\circ}$ (silk II), $20.14^{\circ}$ (silk I), $21.54^{\circ}$ (silk I), or $27.77^{\circ}$ (silk I) (Jin and Kaplan, 2003; Stefan et al., 2019). The peaks in the samples treated with $\mathrm{MeOH}$ and $\mathrm{EtOH}$ have higher intensities compared to those observed in untreated samples, with the intensities in films treated with $\mathrm{MeOH}$ being relatively more pronounced. This suggests a higher degree of crystallinity in $\mathrm{MeOH}$ samples. The same behavior was presented in the work of Nogueira et al. (2010), where they compared the intensities of the untreated samples and those treated with EtOH.

The crystallinity index of the SFW films was calculated using the ratio of the area of the crystalline regions to the total diffraction area (Amiraliyan et al., 2010; Jaramillo-Quiceno and Restrepo-Osorio, 2019) and the results are present in Figure 4. According to the literature, the enrichment of crystalline structures was achieved through post-treatments, resulting in a greater effect on those samples treated with $\mathrm{MeOH}$. This is attributable to the changes from amorphous structures such as random coil to $\beta$ sheet reported for SF films treated by immersion in EtOH (Kaewprasit et al., 2018), MeOH (Çetin Altindal et al., 2019), and saturated vapor from both solvents (Jeong et al., 2006).

\section{Chemical Structure}

Structural changes, attributable to different post-treatments, were studied by FTIR spectra analysis in the region within 1,700$1,200 \mathrm{~cm}^{-1}$ (Supplementary Figures 1, 2). This region is assigned to absorption of the peptide backbones of the Amide I $\left(1,700-1,600 \mathrm{~cm}^{-1}\right)$, the Amide II $\left(1,600-1,500 \mathrm{~cm}^{-1}\right)$, and the Amide III $\left(1,350-1,200 \mathrm{~cm}^{-1}\right)$. All treated samples showed a displacement of the evaluated bands (Table 1), indicating a change in the secondary structures from random coils to $\beta$ sheets.

Additionally, the analysis of Amide I was performed using deconvolution of the peak to determine the proportions in
TABLE 1 | Location of the peaks associated with the secondary structures in the SFW samples and the different treatments.

\begin{tabular}{|c|c|c|c|}
\hline & Random coil & $\beta$ Turn & $\beta$ Sheet \\
\hline Untreated & $1,652,1,538$, and 1,240 & & \\
\hline VEtOH 15 min & $1,640,1,525$, and 1,236 & & \\
\hline VEtOH $1 \mathrm{~h}$ & 1,240 & $\begin{array}{c}1,646 \text { and } \\
1,537\end{array}$ & \\
\hline IEtOH 15 min & $1,642,1,529$, and 1230 & & 1,618 and 1,512 \\
\hline IEtOH 1 h & 1,242 & & 1,622 and 1,515 \\
\hline VMeOH 15 min & $1,642,1,529$, and 1,236 & & \\
\hline VMeOH $1 \mathrm{~h}$ & 1,510 and 1,231 & 1,618 & \\
\hline $\mathrm{IMeOH} 15 \mathrm{~min}$ & 1,236 & & 1,650 and 1,520 \\
\hline $\mathrm{IMeOH} 1 \mathrm{~h}$ & 1,231 & & 1,622 and 1,515 \\
\hline
\end{tabular}

the percentages of the secondary structures of the SFW films without treatment and when treated with $\mathrm{EtOH}$ and $\mathrm{MeOH}$ (Tables 2, 3). Figure 5 presents the total percentages of amorphous and crystalline structures in samples with and without post-treatments. The results obtained from the treated films indicate that all the post-treatments lead to an increase in crystallinity with respect to the untreated films. In all cases, p-values are $<0.05$, indicating statistically significant differences. The results obtained by FTIR confirm those found by means of XRD analysis. Specifically, a greater increase in crystallinity was observed due to post-treatment by immersion compared to with vapor saturated atmosphere. This can be attributed to the greater surface-to-surface interaction of film to solvent. Similarly, a higher percentage of crystalline structures was observed in samples treated by immersion in $\mathrm{MeOH}$. This can be attributed to the greater polarity of $\mathrm{MeOH}$ in comparison to $\mathrm{EtOH}$; as the formation of $\beta$ sheets is favored by the contact of SFW with the solvent of greatest polarity (MeOH) (Jeong et al., 2006). The hydrogen bonds between the water molecules and SFW are rearranged into intermolecular hydrogen bonds within the SFW chains, due to the interaction between water and the organic solvent. EtOH has a lower affinity with water molecules than $\mathrm{MeOH}$, so there is less formation of $\beta$ sheets (Yazawa et al., 2018). Regarding the time of the post-treatments, it was found that $1 \mathrm{~h}$ caused a greater enrichment of crystalline structures. It is suggested that this is caused by a prolonged interaction between the solvents and the SF.

These findings are comparable with those reported by Chankow (2016) and Callone et al. (2016) who found increases in $\beta$ sheets between 10 and $12 \%$ in SFW films treated with EtOH and $\mathrm{MeOH}$. This behavior is attributed to the transformation of random coil into $\beta$ sheets with post-treatments applied (Yali et al., 2014; Maghdouri-White et al., 2016). This is evidenced in the reduction of random coils in the treated samples compared with those untreated.

\section{Thermal Behavior}

To examine the thermal properties, the DSC thermograms for the samples with and without treatment using $\mathrm{EtOH}$ or $\mathrm{MeOH}$, are presented in Supplementary Figures 3, 4, respectively. The temperature values corresponding to the glass transition 
TABLE 2 | Secondary structures percentages of SFW treated with EtOH and untreated films.

\begin{tabular}{|c|c|c|c|c|c|}
\hline & Untreated & VEtOH 15 min & VEtOH 1 h & IEtOH 15 min & IEtOH $1 \mathrm{~h}$ \\
\hline Side chains & $14.3 \pm 0.1$ & $12.5 \pm 1.8$ & $12.8 \pm 1.2$ & $13.4 \pm 0.2$ & $14.8 \pm 2.3$ \\
\hline$\beta$ Sheet & $24.8 \pm 0.8$ & $29.0 \pm 0.1$ & $29.6 \pm 0.4$ & $33.7 \pm 0.9$ & $32.2 \pm 3.1$ \\
\hline Random coil & $21.1 \pm 0.4$ & $17.8 \pm 5.5$ & $14.7 \pm 2.1$ & $11.1 \pm 0.3$ & $9.8 \pm 2.3$ \\
\hline$\alpha$ Helix & $6.7 \pm 0.0$ & $7.5 \pm 2.6$ & $6.4 \pm 1.9$ & $8.9 \pm 0.6$ & $6.6 \pm 2.4$ \\
\hline$\beta$ Turn & $8.4 \pm 0.0$ & $11.9 \pm 0.8$ & $13.5 \pm 1.2$ & $10.3 \pm 0.8$ & $13.1 \pm 3.5$ \\
\hline Turns and bends & $24.4 \pm 0.1$ & $21.0 \pm 4.4$ & $22.8 \pm 1.5$ & $22.5 \pm 1.1$ & $23.1 \pm 1.9$ \\
\hline
\end{tabular}

TABLE 3 | Secondary structures percentages of SFW treated with $\mathrm{MeOH}$ and untreated films.

\begin{tabular}{|c|c|c|c|c|c|}
\hline & Untreated & VMeOH $15 \mathrm{~min}$ & VMeOH $1 \mathrm{~h}$ & IMeOH 15 min & IMeOH $1 \mathrm{~h}$ \\
\hline Side chains & $14.3 \pm 0.1$ & $7.3 \pm 0.8$ & $6.5 \pm 0.2$ & $6.9 \pm 0.7$ & $9.1 \pm 0.8$ \\
\hline$\beta$ Sheet & $24.8 \pm 0.8$ & $33.1 \pm 0.3$ & $35.7 \pm 0.1$ & $39.6 \pm 0.9$ & $42.4 \pm 0.2$ \\
\hline Random coil & $21.1 \pm 0.4$ & $11.1 \pm 0.9$ & $11.0 \pm 0.3$ & $13.3 \pm 0.5$ & $9.1 \pm 1.5$ \\
\hline$\alpha$ Helix & $6.7 \pm 0.0$ & $10.4 \pm 1.4$ & $10.0 \pm 0.9$ & $10.3 \pm 0.1$ & $6.9 \pm 0.7$ \\
\hline$\beta$ Turn & $8.4 \pm 0.0$ & $15.2 \pm 0.5$ & $18.0 \pm 0.7$ & $15.9 \pm 0.8$ & $14.6 \pm 1.0$ \\
\hline Turns and bends & $24.4 \pm 0.1$ & $22.6 \pm 1.1$ & $18.5 \pm 0.5$ & $13.8 \pm 0.2$ & $17.6 \pm 1.3$ \\
\hline
\end{tabular}

temperature $\left(\mathrm{T}_{g}\right)$, the crystallization temperature, and the degradation temperature of the samples studied are included in Table 4. The exothermic recrystallization peak can be evidenced only in the samples without post-treatment and in $\mathrm{VEtOH}$ $15 \mathrm{~min}$. In all the samples, the glass transition and endothermic degradation peaks occurred. In the treated samples there are two endothermic degradation peaks. The first peak is attributed to the degradation of amorphous structures while the second peak is attributed to the crystalline structures present in the material. In a sample without post-treatment, these two events are not completely differentiated.

The $\mathrm{T}_{g}$ occurs at a higher temperature in the treated samples compared to the samples without post-treatment. The highest one corresponding to $\mathrm{IMeOH}\left(165.92^{\circ} \mathrm{C}\right)$ compared to the untreated SFW $\left(144.30^{\circ} \mathrm{C}\right)$, which in turn are the samples with highest and lowest crystallinity, respectively (McGill et al., 2018). This can be explained because, in the samples showing higher crystallinity, the protein chains are in a more compact state and need more energy for the molecular movement of the glass transition to occur (Park et al., 2011). The $\mathrm{T}_{g}$ values obtained in this study are relatively lower than those reported in the literature ( $\mathrm{Lu}$ et al., 2010) which evaluates SF films obtained from silk cocoons and treated with immersion in $\mathrm{MeOH}$. This can be due to the different raw material used in this work as compared to high quality cocoons used in the literature. SFW presents a secondary structure different from that obtained from silk cocoons, on account of the textile transformation processes to which it is subjected (Jaramillo-Quiceno et al., 2017).

As mentioned before, untreated films have a recrystallization peak and the film treated with $\mathrm{VEtOH}$ for 15 min showed a lower recrystallization peak than the untreated films, both near $230^{\circ} \mathrm{C}$. This indicates that there are amorphous secondary structures that can crystallize due to the temperature treatment in the DSC. In other samples the recrystallization peak was not observed, indicating the formation of $\beta$ sheets after post-treatment with both $\mathrm{EtOH}$ and $\mathrm{MeOH}$ in all the other conditions. These results agree with those found in the FTIR ATR analysis.

Degradation peaks of the untreated films appear in the range of $270-272^{\circ} \mathrm{C}$ and for the treated films between $273-277^{\circ} \mathrm{C}$, showing a slight increase in degradation temperatures in the treated samples. This can be attributed to the aforementioned increase in the percentage of crystalline structures in the treated samples, which is consistent with data reported in the literature (Um et al., 2001; Nogueira et al., 2010). These reports indicate a peak of degradation at lower temperatures in untreated samples compared to the degradation peaks of samples treated with solvents. This is due to the higher percentage of amorphous structures in the samples without treatment.

\section{Absorption Water and Weight Loss in Aqueous Medium}

The weight loss and the water absorption in aqueous media of SFW films with and without post treatment were obtained. The results are shown in Table 5. Regarding weight loss, all samples show a greater mass loss on day 7 compared to day 1, as expected. However, the percentages are less than $10 \%$ in both cases. In addition, there is a statistically significant difference for days 1 and 7 in the weight loss of the treated samples compared to the untreated ones with a $p$ value $<0.05$. The weight loss results on day 7 for the untreated samples (9.5\%) were higher with regards to $\mathrm{VEtOH}$ $15 \mathrm{~min}(8.9 \%)$ followed by $\mathrm{VEtOH} 1 \mathrm{~h}(8.7 \%)$, IEtOH $15 \mathrm{~min}$ (8.4\%), IEtOH $1 \mathrm{~h}(7.8 \%), \mathrm{VMeOH} 15 \mathrm{~min}$ (7.4\%), VMeOH $1 \mathrm{~h}$ (7.2\%), IMeOH $1 \mathrm{~min}$ (6.2\%), and finally $\mathrm{IMeOH} 1 \mathrm{~h}$ (5.3\%). The values obtained for the untreated samples, and samples treated with $\mathrm{IMeOH}$ for $1 \mathrm{~h}$ are similar to those reported in the literature by Srivastava et al. (2015). Moreover, Mandal et al. (2009) and Zhou et al. (2016) reported a nonsignificant loss in $\mathrm{IMeOH}$ and $10 \%$ in untreated films. On the other hand, samples treated with $\mathrm{EtOH}$ showed a mass 


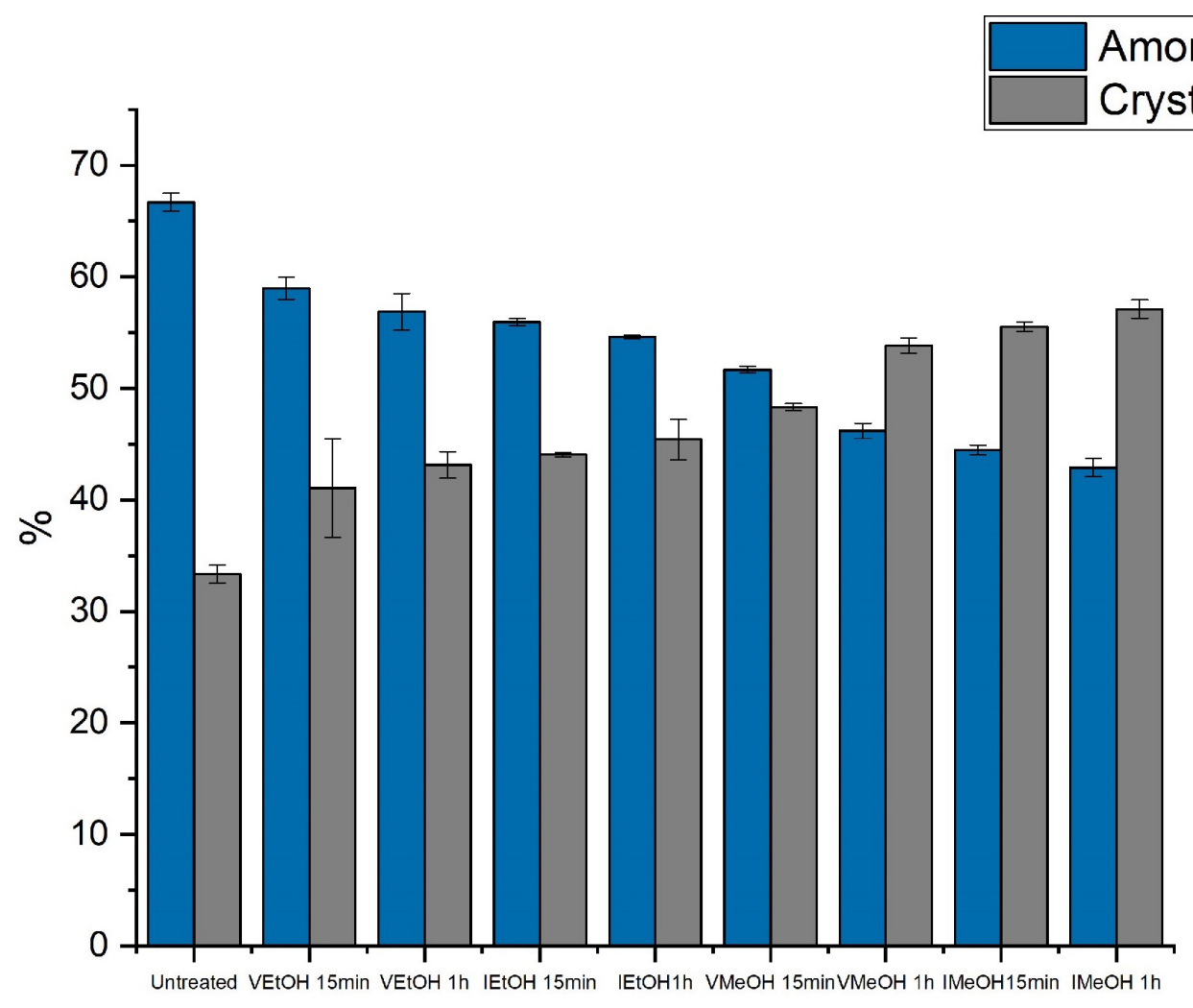

FIGURE 5 | FTIR amorphous and crystalline structures of treated and untreated SFW films.

TABLE 4 | Summary of DSC data obtained from films with different post-treatments.

\begin{tabular}{lcccc}
\hline & $\mathbf{T}_{\boldsymbol{g}}\left(\mathbf{}^{\circ} \mathbf{C}\right)$ & $\begin{array}{c}\mathbf{T}_{\text {crystallization }} \\
\left({ }^{\circ} \mathbf{C}\right)\end{array}$ & $\begin{array}{c}\mathbf{T}_{\text {degradation }} \\
\left({ }^{\circ} \mathbf{C}\right)\end{array}$ & $\begin{array}{c}\mathbf{T}_{\text {degradation 2 }} \\
\left({ }^{\circ} \mathbf{C}\right)\end{array}$ \\
\hline Untreated & 144.30 & 229.59 & 255.80 & 272.98 \\
VEtOH 15 min & 151.20 & 231.80 & 258.13 & 273.47 \\
VEtOH 1 h & 151.61 & - & 256.65 & 273.05 \\
IEtOH 15 min & 152.75 & - & 258.00 & 275.32 \\
IEtOH 1 h & 153.11 & - & 258.11 & 273.12 \\
VMeOH 15 min & 153.90 & - & 256.72 & 274.37 \\
VMeOH 1 h & 160.73 & - & 259.47 & 274.29 \\
IMeOH 15 min & 164.45 & - & 257.01 & 274.82 \\
IMeOH 1 h & 165.92 & - & 260.10 & 276.73 \\
\hline
\end{tabular}

loss between 7 and $8 \%$, a percentage comparable to that reported by Rajkhowa et al. (2011).

The water absorption results show a similar trend to that which was previously observed, corresponding to degradation. There was a higher absorption of water observed in untreated samples (34.9\%), followed by VEtOH $15 \mathrm{~min}(32.1 \%)$, VEtOH $1 \mathrm{~h}$ (30.1\%), IEtOH $15 \mathrm{~min}$ (28.1\%), IEtOH $1 \mathrm{~h}$ (25.4\%), VMeOH $15 \mathrm{~min}(22.8 \%), \mathrm{VMeOH} 1 \mathrm{~h}$ (19.8\%), IMeOH $15 \mathrm{~min}$ (17.2\%), and finally $\mathrm{IMeOH} 1 \mathrm{~h}(15 \%)$. This can be attributed to the fact that samples treated with $\mathrm{MeOH}$ have a higher percentage of crystalline structures, which makes them more hydrophobic
TABLE 5 | Results of weight loss films and water absorption films of SFW.

\begin{tabular}{|c|c|c|c|c|}
\hline & \multicolumn{2}{|c|}{ Weight loss (\%) } & \multicolumn{2}{|c|}{ Water absorption (\%) } \\
\hline & D1 & D7 & D1 & D7 \\
\hline Untreated & $8.52 \pm 0.56$ & $9.55 \pm 0.32$ & $30.65 \pm 0.94$ & $34.91 \pm 0.39$ \\
\hline VEtOH 15 min & $7.70 \pm 0.92$ & $8.91 \pm 0.11$ & $29.32 \pm 0.79$ & $32.16 \pm 0.51$ \\
\hline VEtOH $1 \mathrm{~h}$ & $7.15 \pm 0.55$ & $8.74 \pm 0.20$ & $27.66 \pm 0.77$ & $30.12 \pm 0.04$ \\
\hline IEtOH 15 min & $6.47 \pm 0.18$ & $8.43 \pm 0.19$ & $25.47 \pm 0.71$ & $28.15 \pm 0.57$ \\
\hline $\mathrm{IEtOH} 1 \mathrm{~h}$ & $5.88 \pm 0.43$ & $7.82 \pm 0.53$ & $22.26 \pm 1.46$ & $25,46 \pm 0.26$ \\
\hline VMeOH $15 \mathrm{~min}$ & $4.47 \pm 0.02$ & $7.40 \pm 0.22$ & $19.23 \pm 0.51$ & $22.83 \pm 0.34$ \\
\hline VMeOH $1 \mathrm{~h}$ & $4.13 \pm 0.14$ & $7.25 \pm 0.28$ & $16.82 \pm 0.67$ & $19.82 \pm 0.95$ \\
\hline $\mathrm{IMeOH} 15 \mathrm{~min}$ & $2.82 \pm 0.19$ & $6.26 \pm 0.29$ & $14.14 \pm 0.92$ & $17.21 \pm 0.64$ \\
\hline $\mathrm{IMeOH} 1 \mathrm{~h}$ & $1.64 \pm 1.64$ & $5.38 \pm 5.38$ & $12.70 \pm 0.41$ & $15.03 \pm 0.05$ \\
\hline
\end{tabular}

compared to those treated with vapor and untreated samples. There is a statistically significant difference on day 7 in the treated samples compared to the untreated ones, with a $p$ value $<0.05$. Srivastava et al. (2015), Bagrov et al. (2017), and Bie et al. (2015) reported absorption in samples treated with $15 \% \mathrm{MeOH}$ and untreated between 36 and 46\%, respectively. These values are similar to those obtained in this study.

\section{Scanning Electron Microscopy}

Scanning electron microscopy micrographs (Figure 6) showed a change in the surface morphology of films 

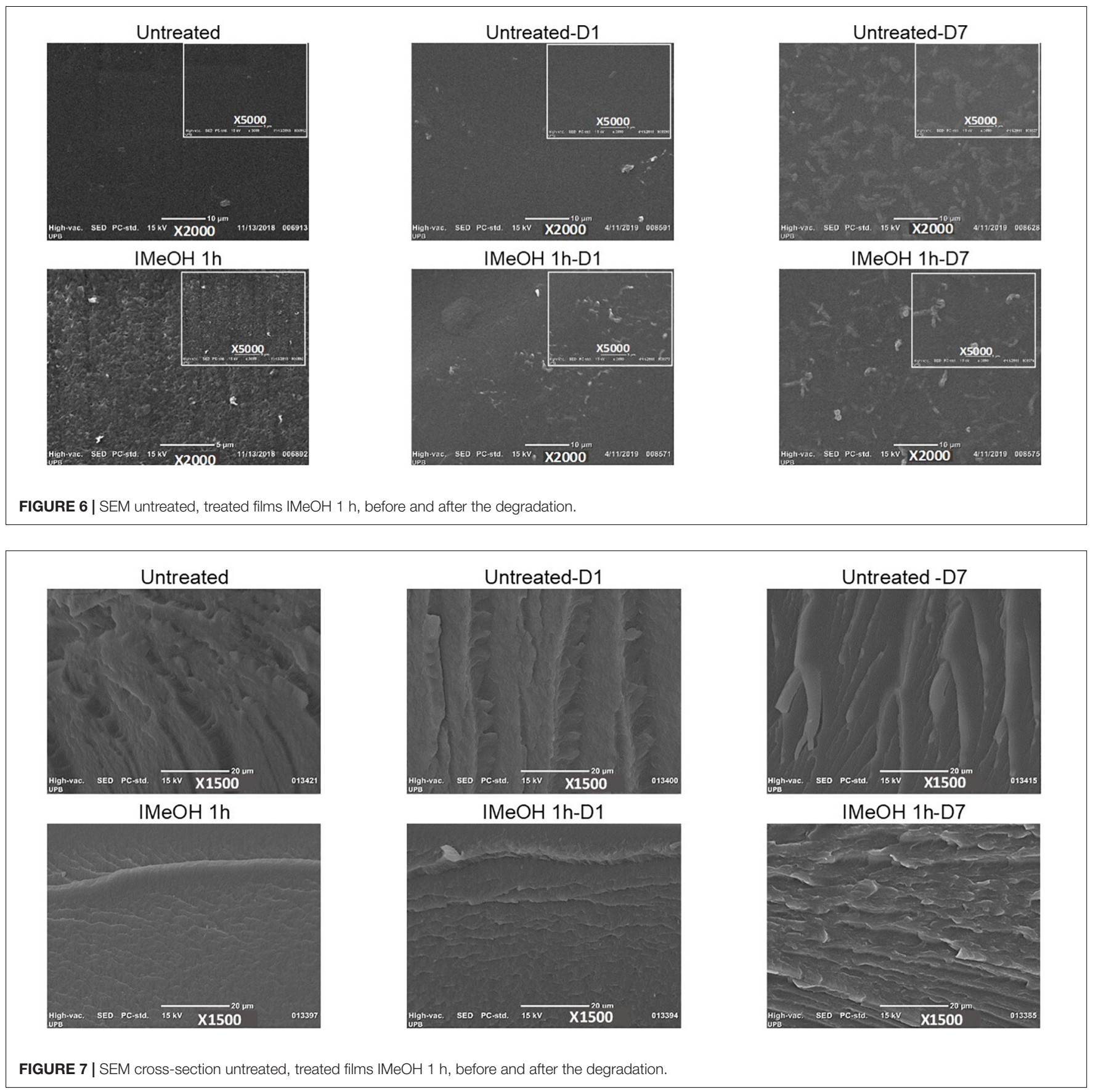

treated by immersion in $\mathrm{MeOH}$ for $1 \mathrm{~h}$, changing from a smooth to a rough surface, due to the contraction of the proteinaceous material. This phenomenon can be explained by the hydrophobic dehydration that occurs due to molecular interactions between protein chains and the polar solvent (Chen et al., 2009). These results are in agreement with those reported in the literature by Terada et al. (2016) and Wongpanit et al. (2007) who reported a rougher surface when using immersion post-treatments with more than $90 \%$ EtOH and $\mathrm{MeOH}$ respectively, which could potentially rebound in the cell adhesion (Wongpanit et al., 2007; Terada et al., 2016).

In addition, SFW films treated by immersion (Supplementary Figures 5, 6) show a higher roughness compared to those treated by saturated vapor (Supplementary Figures 7, 8), given the large density of molecules of solvent in the liquid state. This could suggest higher interaction between the SF film and the solvent. On the other hand, post-treatments with $\mathrm{MeOH}$ (Supplementary Figures 5, 7) cause a more noticeable change due to the higher polarity of $\mathrm{MeOH}$ compared to that of $\mathrm{EtOH}$ (Supplementary Figures 6, 8). This allows for easier interactions 
between water molecules and the solvent with higher polarity. The change in morphology is related to the structural and thermal changes discussed above. This is because the films that presented a greater apparent roughness in the SEM images are the same that presented a higher percentage of crystalline structures, along with a higher degradation temperature. Thus, this indicates that the immersion treatment with $\mathrm{MeOH}$ provides greater changes in the properties evaluated when compared to the other treatments.

The films morphology was also studied after the exposure of samples for 1 and 7 days, in the corresponding SEM images (Figure 6 and Supplementary Figures 5-8). It can be observed on day 1 what appears to be the swelling of the surface with a decrease in roughness, which can be attributed to the water absorption of the films. Moreover, on day 7, erosion is evident on the surface, showing some cavities and surface agglomerations caused by swelling and potentially by the solubilization process, which is consistent with results reported in the literature (Zhou et al., 2016; Wang et al., 2019). According to the content of secondary structures present in SFW films, there are significant changes in morphology (Minoura et al., 1990; Lu et al., 2010), with films post-treated with EtOH having the most evident differences. Those films show a higher content of amorphous structures, compared to those treated with $\mathrm{MeOH}$, which favors higher weight loss values, as presented above.

The images obtained by SEM (Figure 7 and Supplementary Figures 9-12) of the cross-section show changes in the striations of the samples, with narrower filaments/striations and more compacting in the samples with a higher percentage of crystallinity (IMeOH, Supplementary Figure 9). In contrast, as the samples decrease in their percentage of crystallinity, the size of striae become wider (EtOH treated samples, Supplementary Figures 11, 12). These results confirm our observations regarding the dependence on the morphology of the films cross-sections and the percentage of the crystalline structures, and are also consistent with those previously reported (Zhang et al., 2012). Zhang et al. (2012) had shown that films with greater crystallinity present a more regular compact morphology.

\section{CONCLUSION}

The effects of post-treatment with $\mathrm{EtOH}$ and $\mathrm{MeOH}$ at different times, by immersion and saturated atmosphere on the SFW films, were evaluated. The change in the percentage of secondary structures and their influence on degradation rates and thermal properties were determined. The results obtained indicate that the treatments evaluated in this study are effective in increasing the content of the crystalline structure, evidenced in the reduction of random coils and the increase of $\beta$ sheets as demonstrated by XRD and FTIR. Therefore, treatments with organic solvents present an effective mechanism to regulate the crystallinity, water integrity and thermal stability of the material.

Among the post-treatments studied, immersion in $\mathrm{MeOH}$ for $1 \mathrm{~h}$ provided the highest increase in percentage of crystalline structures with a value of $57.1 \%$ compared to $33.3 \%$ of the sample without treatment. This increase also indicates that films with higher percentage of crystalline structures also show higher degradation temperatures, as well as decreased degradation and water absorption rates when compared to untreated samples.

These results are relevant for applications of SF from SFW in biomedicine, such as cellular scaffolding, as regulated degradation rates and mechanical and thermal stability are required to allow adhesion, cell proliferation, and durability of scaffolding.

Films obtained from fibrous wastes showed similar properties to those reported for SF extracted from cocoons, indicating that materials manufactured from wastes have the potential to be used in biomedical applications. Additionally, the results obtained from this study can aid in improving the sustainability of the sericultural chain, especially regarding small scale production, allowing for better utilization of resources and increased value of the material.

\section{DATA AVAILABILITY STATEMENT}

The datasets generated for this study are available on request to the corresponding author.

\section{AUTHOR CONTRIBUTIONS}

MP developed the materials and performed the experiments and characterizations. MP, MSP, and AR-O contributed to the conceptualization, data analysis, and writing of the manuscript. All authors listed have made a substantial, direct and intellectual contribution to the work, and approved it for publication.

\section{FUNDING}

This research received financial support to Ministerio de Ciencia y Tecnología (MINCIENCIAS) of the research project 121080762864. Additional support from the Alabama Experimental Station, the HATCH Program (ALA013-117003), and the McIntire Stennis Program (ALAZ00076) of the National Institute of Food and Agriculture, United States Department of Agriculture.

\section{ACKNOWLEDGMENTS}

Acknowledgments to Centro de Investigación para el Desarrollo y la Innovación (CIDI) of the Universidad Pontificia Bolivariana for financial the advanced training scholarship for the master's student to MP.

\section{SUPPLEMENTARY MATERIAL}

The Supplementary Material for this article can be found online at: https://www.frontiersin.org/articles/10.3389/fbioe.2020. 523949/full\#supplementary-material 


\section{REFERENCES}

Adali, T., and Uncu, M. (2016). Silk fibroin as a non thrombogenic biomaterial. Int. J. Biol. Macromol. 90, 11-19. doi: 10.1016/j.ijbiomac.2016.01.088

Amiraliyan, N., Nouri, M., and Kish, M. H. (2010). Structural characterization and mechanical properties of electrospun silk fibroin nanofiber mats. Polym. Sci. Ser. A 52, 407-412. doi: 10.1134/S0965545X10040097

Babu, K. M. (2013). Silk: Processing, Properties and Applications. Sawston: Woodhead Publishing Limited. doi: 10.1533/9781782421580

Bagrov, D., Zhuikov, V., Chudinova, Y., Yarisheva, A., Kotlyarova, M., and Arkhipova, A. (2017). Mechanical properties of films and three-dimensional scaffolds made of fibroin and gelatin. Mol. Biophys. 62, 17-23. doi: 10.1134/ S0006350917010031

Bhardwaj, N., Sow, W. T., Devi, D., Ng, K. W., Mandal, B. B., and Cho, N. J. (2015). Silk fibroin-keratin based $3 \mathrm{D}$ scaffolds as a dermal substitute for skin tissue engineering. Integr. Biol. (United Kingdom) 7, 53-63. doi: 10.1039/c4ib00208c

Bie, S., Ming, J., Zhou, Y., Zhong, T., Zhang, F., and Zuo, B. (2015). Rapid formation of flexible silk fibroin gel-like films. J. Appl. Polym. Sci. 41842, 2-9. doi: 10.1002/app.41842

Bonani, W., Maniglio, D., Motta, A., Tan, W., and Migliaresi, C. (2011). Biohybrid nanofiber constructs with anisotropic biomechanical properties. J. Biomed. Mater. Res. Part B Appl. Biomater. 96 B, 276-286. doi: 10.1002/jbm.b.31763

Callone, E., Dire, S., Hu, X., and Motta, A. (2016). Processing influence on molecular assembling and structural conformations in silk fibroin: elucidation by solid-state NMR. ACS Biomater. Sci. Eng. 2, 758-767. doi: 10.1021/ acsbiomaterials.5b00507

Çetin Altındal, D., James, E. N., Kaplan, D. L., and Gümüşderelioğlu, M. (2019). Melatonin-induced osteogenesis with methanol-annealed silk materials. J. Bioact. Compat. Polym. 34, 291-305. doi: 10.1177/0883911519847489

Chankow, S. (2016). "Conformational transitions of thai silk fibroin secondary structures," in Biomedical Engineering International Conference (BMEiCON2016), Vol. 89, Laung Prabang, 25-34.

Chen, X., Knight, D. P., and Shao, Z. (2009). B -turn formation during the conformation transition in silk fibroin. R. Soc. Chem. 5, 2777-2781. doi: 10. 1039/b900908f

Fukayama, T., Takagi, K., Tanaka, R., Hatakeyama, Y., Aytemiz, D., Suzuki, Y., et al. (2015). Biological reaction to small-diameter vascular grafts made of silk fibroin implanted in the abdominal aortae of rats. Ann. Vasc. Surg. 29, 341-352. doi: $10.1016 /$ j.avsg.2014.10.008

Ha, S. W., Tonelli, A. E., and Hudson, S. M. (2005). Structural studies of Bombyx mori silk fibroin during regeneration from solutions and wet fiber spinning. Biomacromolecules 6, 1722-1731. doi: 10.1021/bm050010y

Huang, Y., Bailey, K., Wang, S., and Feng, X. (2017). Silk fibroin films for potential applications in controlled release. React. Funct. Polym. 116, 57-68. doi: 10.1016/ j.reactfunctpolym.2017.05.007

Jaramillo-Quiceno, N., Álvarez-López, C., and Restrepo-Osorio, A. (2017). Structural and thermal properties of silk fibroin films obtained from cocoon and waste silk fibers as raw materials. Proc. Eng. 200, 384-388. doi: 10.1016/j. proeng.2017.07.054

Jaramillo-Quiceno, N., and Restrepo-Osorio, A. (2019). Water-annealing treatment for edible silk fibroin coatings from fibrous waste. J. Appl. Polym. Sci. 137:48505. doi: 10.1002/app.48505

Jeong, L., Lee, K. Y., Liu, J. W., and Park, W. H. (2006). Time-resolved structural investigation of regenerated silk fibroin nanofibers treated with solvent vapor. Int. J. Biol. Macromol. 38, 140-144. doi: 10.1016/j.ijbiomac.2006.02.009

Jin, H. J., and Kaplan, D. L. (2003). Mechanism of silk processing in insects and spiders. Nature 424, 1057-1061. doi: 10.1038/nature01809

Kaewprasit, K., Kobayashi, T., and Damrongsakkul, S. (2018). Thai silk fibroin gelation process enhancing by monohydric and polyhydric alcohols. Int. J. Biol. Macromol. 118, 1726-1735. doi: 10.1016/J.IJBIOMAC.2018.07.017

Kim, J. H., Park, C. H., Lee, O. J., Lee, J. M., Kim, J. W., Park, Y. H., et al. (2012). Preparation and in vivo degradation of controlled biodegradability of electrospun silk fibroin nanofiber mats. J. Biomed. Mater. Res. Part A 100 A, 3287-3295. doi: 10.1002/jbm.a.34274

Ko, Y. G., Lee, M., Park, W. H., Cho, D., Kwon, O. K., and Kwon, O. H. (2016). Guiding bone regeneration using hydrophobized silk fibroin nanofiber membranes. Macromol. Res. 24, 824-828. doi: 10.1007/s13233-016-4109-2

Lu, Q., Hu, X., Wang, X., Kluge, J. A., Lu, S., Cebe, P., et al. (2010). Waterinsoluble silk films with silk I structure. Acta Biomater. 6, 1380-1387. doi: 10.1016/j.actbio.2009.10.041
Maghdouri-White, Y., Bowlin, G. L., Lemmon, C. A., and Dréau, D. (2016). Bioengineered silk scaffolds in 3D tissue modeling with focus on mammary tissues. Mater. Sci. Eng. C 59, 1168-1180. doi: 10.1016/j.msec.2015.10.007

Mandal, B. B., Mann, J. K., and Kundu, S. C. (2009). Silk fibroin/gelatin multilayered films as a model system for controlled drug release. Eur. J. Pharm. Sci. 37, 160-171. doi: 10.1016/j.ejps.2009.02.005

McGill, M., Holland, G. P., and Kaplan, D. L. (2018). Experimental methods for characterizing the secondary structure and thermal properties of silk proteins. Macromol. Rapid Commun. 40, 1-14. doi: 10.1002/marc.201800390

Minoura, N., Tsukada, M., and Nagura, M. (1990). Physico-chemical properties of silk fibroin membrane as a biomaterial. Biomaterials 11, 430-434. doi: 10.1016/0142-9612(90)90100-5

Nogueira, G. M., Rodas, A. C. D., Leite, C. A. P., Giles, C., Higa, O. Z., Polakiewicz, B., et al. (2010). Preparation and characterization of ethanol-treated silk fibroin dense membranes for biomaterials application using waste silk fibers as raw material. Bioresour. Technol. 101, 8446-8451. doi: 10.1016/j.biortech.2010. 06.064

Panico, A., Paladini, F., and Pollini, M. (2018). Development of regenerative and flexible fibroin-based wound dressings. J. Biomed. Mater. Res. B Appl. Biomater. 107, 7-18. doi: 10.1002/jbm.b.34090

Park, S., Kaplan, D. L., Hu, X., Shmelev, K., Sun, L., Gil, E., et al. (2011). Regulation of silk material structure by temperature-controlled water vapor annealing regulation of silk material structure by temperature-controlled water vapor annealing. Biomacromolecules 12, 1686-1696. doi: 10.1021/bm2 $00062 \mathrm{a}$

Rajkhowa, R., Levin, B., Redmond, S. L., Li, L. H., Wang, L., Kanwar, J. R., et al. (2011). Structure and properties of biomedical films prepared from aqueous and acidic silk fibroin solutions. J. Biomed. Mater. Res. A 97, 37-45. doi: 10. 1002/jbm.a.33021

Rockwood, D. N., Preda, R. C., Yücel, T., Wang, X., Lovett, M. L., and Kaplan, D. L. (2011). Materials fabrication from Bombyx mori silk fibroin. Nat. Protoc. 6, 1612-1631. doi: 10.1038/nprot.2011.379

Srivastava, C. M., Purwar, R., Kannaujia, R., and Sharma, D. (2015). Flexible silk fibroin films for wound dressing. Fibers Polym. 16, 1020-1030. doi: 10.1007/ s12221-015-1020-y

Stefan, N., Miroiu, F. M., and Socol, G. (2019). Degradable silk fibroin - poly (sebacic acid) diacetoxy terminated, (SF-PSADT) polymeric composite coatings for biodegradable medical applications deposited by laser technology. Prog. Org. Coatings 134, 11-21. doi: 10.1016/j.porgcoat.2019.04.075

Tao, H., Kaplan, D. L., and Omenetto, F. G. (2012). Silk materials-a road to sustainable high technology. Adv. Mater. 24, 2824-2837. doi: 10.1002/adma. 201104477

Terada, D., Yokoyama, Y., Hattori, S., Kobayashi, H., and Tamada, Y. (2016). The outermost surface properties of silk fibroin films reflect ethanol-treatment conditions used in biomaterial preparation. Mater. Sci. Eng. C 58, 119-126. doi: 10.1016/j.msec.2015.07.041

Um, I. C., Kweon, H., Park, Y. H., and Hudson, S. (2001). Structural characteristics and properties of the regenerated silk fibroin prepared from formic acid. Int. J. Biol. Macromol. 29, 91-97. doi: 10.1016/S0141-8130(01)00159-3

Unger, R. E., Peters, K., Wolf, M., Motta, A., Migliaresi, C., and Kirkpatrick, C. J. (2004). Endothelialization of a non-woven silk fibroin net for use in tissue engineering: growth and gene regulation of human endothelial cells. Biomaterials 25, 5137-5146. doi: 10.1016/j.biomaterials.2003.12.040

Wang, L., Luo, Z., Zhang, Q., Guan, Y., Cai, J., You, R., et al. (2019). Effect of degumming methods on the degradation behavior of silk fibroin biomaterials. Fibers Polym. 20, 45-50. doi: 10.1007/s12221-019-8658-9

Wongpanit, P., Tabata, Y., and Rujiravanit, R. (2007). Miscibility and biodegradability of silk fibroin/carboxymethyl chitin blend films. Macromol. Biosci. 7, 1258-1271. doi: 10.1002/mabi.200700074

Wu, T., Zhang, J., Wang, Y., Li, D., Sun, B., El-Hamshary, H., et al. (2018). Fabrication and preliminary study of a biomimetic tri-layer tubular graft based on fibers and fiber yarns for vascular tissue engineering. Mater. Sci. Eng. C 82, 121-129. doi: 10.1016/j.msec.2017.08.072

Yali, W., Dan, S., Honggen, Y., and Jiannan, W. (2014). Characterization of a PEGDE cross-linked tubular silk scaffold. Text. Res. J. 84, 959-967. doi: 10.1177/ 0040517513512401

Yan, L. P., Oliveira, J. M., Oliveira, A. L., Caridade, S. G., Mano, J. F., and Reis, R. L. (2012). Macro/microporous silk fibroin scaffolds with potential for articular cartilage and meniscus tissue engineering applications. Acta Biomater. 8, 289-301. doi: 10.1016/j.actbio.2011.09.037 
Yang, H., Yang, S., Kong, J., Dong, A., and Yu, S. (2015). Obtaining information about protein secondary structures in aqueous solution using Fourier transform IR spectroscopy. Nat. Protoc. 10, 382-396. doi: 10.1038/nprot.20 15.024

Yazawa, K., Malay, A. D., Ifuku, N., Ishii, T., Masunaga, H., Hikima, T., et al. (2018). Combination of amorphous silk fiber spinning and postspinning crystallization for tough regenerated silk fibers. Biomacromolecules 19, 2227-2237. doi: 10. 1021/acs.biomac. 8 b00232

Zhang, C., Song, D., Lu, Q., Hu, X., Kaplan, D. L., and Zhu, H. (2012). Flexibility regeneration of silk fibroin in vitro. Biomacromolecules 13, 2148-2153. doi: 10.1021/bm300541g

Zhang, X., Reagan, M. R., and Kaplan, D. L. (2009). Electrospun silk biomaterial scaffolds for regenerative medicine. Adv. Drug Deliv. Rev. 61, 988-1006. doi: 10.1016/j.addr.2009.07.005
Zhou, J., Zhang, B., Liu, X., Shi, L., Zhu, J., Wei, D., et al. (2016). Facile method to prepare silk fibroin/hyaluronic acid films for vascular endothelial growth factor release. Carbohydr. Polym. 143, 301-309. doi: 10.1016/j.carbpol.2016.01.023

Conflict of Interest: The authors declare that the research was conducted in the absence of any commercial or financial relationships that could be construed as a potential conflict of interest.

Copyright (c) 2020 Puerta, Peresin and Restrepo-Osorio. This is an open-access article distributed under the terms of the Creative Commons Attribution License (CC BY). The use, distribution or reproduction in other forums is permitted, provided the original author(s) and the copyright owner(s) are credited and that the original publication in this journal is cited, in accordance with accepted academic practice. No use, distribution or reproduction is permitted which does not comply with these terms. 